\title{
Places of Heritage in Cities: The Challenge of Planning Based on Their Sustainable Urban Integration
}

\author{
Maria Markatou \\ School of Architecture, National Technical University of Athens, Athens GR-15780, Greece
}

\begin{abstract}
The paper examines a case study of a monument of cultural heritage, which includes elements of historical, architectural and rural landscape, as well as other material and intangible elements. The monument, named "Averofios Agricultural School", is located within the urban area of Larissa, on its outskirts. The school, established in 1901, operates as an educational agricultural organization, has been declared to be preserved by the Greek Ministry of Culture and its management involves five different public institutions. The main issue is that the school is at risk of depreciation due to degrading phenomena and its further isolation. The paper argues that its obsolescence could be stopped if the area could be integrated into the city of Larissa from the urban, operational, educational and strategic point of view. For this purpose, it is proposed to regenerate the area and to use it as a peri-urban rural educational park with local, regional and national scope.
\end{abstract}

Key words: Agricultural educational park, cultural heritage, urban planning, urban regeneration.

\section{Introduction}

The retention and conservation of cultural heritage was once limited to monuments, archaeological sites and mobile collections of heritage. Nowadays, however, its notion has expanded and includes urban, historical areas, local folk-nature heritage, cultural city spaces, even living aspects of culture as well as every aspect of cultural heritage as it occurs from the natural and mental relation between people, societies and their environment. From the above emerges that cultural heritage is characterized both by material and intangible elements [1]. The retention and conservation of cultural heritage helps a community not only with the fact that offers it conservation tools of the financially significant resources but also with the retention of local practices, the history and the environment along with a sense of continuity and distinct identity [2].

Culture "matters" today, as well, more than ever. It matters for the cities which constitute the driving

Corresponding author: Maria Markatou, Dr. (Lecturer), Head of the Directorate of Urban Planning, research fields: urban and landscape planning. forces of contemporary society. Culture is a fully complete financial sector, which as any other sector produces results in the urban environment, both positive and negative, which vary from direct and indirect financing to the production of employment [3]. For this reason, cities are considered advantaged places targeting cultural production and consumption. At the same time, culture can contribute to a balanced and sustainable urban development, since international experience has shown that it constitutes part of and a "gift" to plans and projects for urban regeneration, as they are developed in inner-cities in developed countries $[4,5]$.

In this framework, cultural development and planning are faced as valuable strategies for the acceleration of urban development and regeneration functions. Cities invest in cultural services, functions and events, as well as in the retention and conservation of cultural heritage so as to make an easier and faster transition to the so-called post-industrial economy, which is based on advanced services, the blending of sustainable and functional land usages and the high quality urban environment [6]. 
This means that decision makers as well as those with direct and indirect vested interests have to know the whole "theory" behind the interpretation of culture as a financial asset for the city, to detect the source of the whole problem and determine any synergies between cultural and local development, so that they can activate and promote them.

Nowadays, literature on the connection between culture and city is extensive. For example, studies such as those of "The Rise of the Creative Class" [7], "The Cultural Economy of Cities" [8] are all based on a new perspective which prescribes a new way of conceiving the relationship between culture and place or space. For example, Allen J. Scott differentiates and modifies the discussion about culture and when he refers to it he uses the term "urban good" or group of financial sectors which find a scope of activity in cities, taking up a central role in the regeneration procedures and producing value through feeding international functions which are based and depend on the creation of an image and the tools of its assessment (e.g. tourism, recreation, mass media).

The impact of this new "cultural economic example", regarding urban development on terms of opportunities and threats, is under examination and exploration; however, in any case, they require the breaking away of urban planning from traditional concepts and stereotypes. Simultaneously, it becomes widely acceptable that cultural heritage constitutes significant capital, with a lot of benefits for the countries and the cities, where its goods are sited [9]. In this framework, planning requires something more that protection measures and actions against human activity and various burdens. On the contrary, it entails measures and actions of development and utilization and, therefore, inclusion of cultural goods into the social and economic development of a city, and area or a country [10]. This, however, eventually means that urban planning through an eternal process becomes more complete and at the same time more complex.

\section{Study Details and Objective}

The study examines and analyzes the case of "Averofios Agricultural School", which is a cultural monument. It is a neoclassical complex of buildings on the west city entrance next to buildings of TEI (Technological Educational Institution) of Thessaly. The complex is surrounded by a wood of pine trees. Among its special features is the impressive central neoclassical building with a clock. The construction of the school buildings was made at the expenses of the legacy left by the benefactor Georgios Averof in the beginning of the 19th century and it operated as a Secondary Agriculture School until the middle of the 20th century. The complex of "Averofios" school and its surrounding area was designated a work of art and a historic listed monument because it constitutes a distinguished and representative sample of building complex of educational character, with special morphological, architectural characteristics and elements of eclecticism which characterize it architectural era. It is considered unique for the area and an integral part of its residents' memories.

However, despite the significance of the monument for the city of Larissa and the greater area, the present image of the School is bad and this bad image is, first of all, connected with the bad condition of its buildings, which, as was already mentioned, have been designated as listed monuments. Thus, the architecturally distinct buildings of the complex, such as the central building with the clock, which is emblematic of the "school", the old library with its impressive flight of stairs as but the other buildings as well have sustained severe damage and weathering due to neglect, as time goes by. The sight of the School is depressive and the collapse of the buildings is just a matter of time. We should point out here that according to the City Planning Service of Larissa several of the buildings have been deemed dangerous.

The basic hypothesis of this study is that Averofios Agricultural School is an asset for the city of Larissa and the region in general. It is not just its building stock 
which is worth preserving. It is a school that remained alive in the passing of time despite various problems. A simple visit to the place can make it clear to you that part of the Greek industrial and agricultural history lies there. The study deems that the history of the School and what it potentially offers, at least, to the local community are its most important asset and what must be featured so that it meets the demands of contemporary community and economy. In any case, its value must not be further depreciated, and its development is considered necessary and unavoidable. In this framework, the basic proposal consists of developing the School into an agricultural educational park, that is, a modern center providing agricultural education, training and, mainly, entrepreneurship for young or older men and women farmers as well as other citizens of the greater area, in which plan also includes tourism actions, clearly for sustainability reasons.

However, every proposal for the "renaissance" of Averofios Agricultural School bears little to zero possibility of success if the School is not integrated with the city of Larissa, first of all. Its integration constitutes the first step so that through specific deeds and actions it will manage to become a benchmark in the greater area and, in this framework, Larissa's identity becomes liked with the School. It must be noted, at this point, that by "integration" of the School we mean its integration in the urban planning of the city of Larissa and its functional and educational integration in the cluster of the other educational and research units and structures (for example the Technical Institute of Thessaly, the University of Thessaly and CERTH-Centre for Research and Technology of Hellas) and a strategy towards this integration (integration in and connection with the broader planning of the Municipality of Larissa, as a political entity of local authority and administration, as it is described in the City Branding and Marketing plan of Larissa and in ISUDS (Integrated Sustainable Urban Development Strategies).
Finally, it must be emphasized that the analysis and the proposal of the case study of Averofios Agricultural School are not based on an existing or in progress study or reference article. From a survey contacted for the needs of the present study turned out that the School was never included in an academic or research text, except for one doctoral dissertation which, however, focused on the matter of agricultural education in Greece and in this framework the School was studied. Consequently, the text that follows is based on our own research and the opinions included are clearly personal.

\section{The "Averofios Agricultural School": Georgios Acerof's Bequest, the Past and the Present}

\subsection{Georgios Averof’s Bequest}

Averofios Agricultural School owes its existence to the legacy left by our national benefactor Georgios Averof through his will. Specifically, after his bequeathed part of his real estate to his relatives and to the Greek community of Alexandria, mainly for the preservation of Averofion High School and Averofeon Girls' School as well as other educational institutes of the community, he allocated the rest of his property, chattel and real estate, into 80 shares, four of which were earmarked for the establishment and preservation of the Agricultural School. Who was Georgios Averof, though?

Georgios Averof, born as Georgios Avgeros Apostolakas, was born in Metsovon on 15th August, 1815 and died in Alexandria, Egypt in 1899. He was a Greek entrepreneur. From Metsovon he moved to Alexandria at the age of 19 and settled in Kairo in order to work in his brother's, Anastasios, cloth shop and traded cotton. Georgios Averof is considered one of the greatest benefactors of Greece. Through his will, which was drawn up by himself, on 10/30 of March, 1898 and was notarized by the Greek Consulate Court in Alexandria on $16 / 28$ of July 1899 , the next day after his death, he donated sound sums of money 
targeted at charities, social works and the establishment of educational and other infrastructure, both in Egypt (for the Greek community of Alexandria) and in Greece (Metsovon, Athens and other areas in the Greek State).

Consequently, Georgios Averof in his will offered a specific amount of his property for the establishment of an Agricultural School in Larissa, that is, he prescribed the target of his bequeathed money (the building of an Agricultural School) as well as the location where this target should be materialized (the city of Larissa). At this point it should be underlined that according to the Public Benefit Purpose Entities code, School/Scholastic inheritance and other provisions, which is a continuity of the constitutional context that existed back then, the Government had and still has the responsibility to safeguard the accurate implementation of the testators' and benefactors' will. Therefore, the stipulations concerning the "establishment of the agricultural school" in "the city of Larissa" were binding.

\subsection{An Historical Flash-Back}

A specific law of 1901 accommodated the establishment of an agricultural school in Larissa bearing the name "Averofios Agricultural School of Larissa". Of course, as it is easily understood, Larissa was then an area with different problems from contemporary agriculture. Averofios Agricultural School was established in 1901 but its operation began in 1911 .

VOLE' law of 18/20 February, 190134 accommodated the establishment of the Agricultural School of Larissa at the expenses of the bequest bearing the name "Averofios Agricultural School of Larissa". Article 2 stipulated the use of the capital of the bequest for the purchase of three thousand acres for the establishment of the school, the construction of buildings, the purchase of furniture, utensils, tools and equipment; while article 3 concerned the preservation of the school, which was ensured by the annual interest of the bequest, by the earnings of the school from the sales of products, by the fees and tuition paid by the students and by the government's subsidy which came up to 25,000 drachmas, in case the other earnings were not enough to ensure its preservation.

According to the establishing law, the purpose of the school was the education of agriculturists who, after their graduation, would be able to be involved in agriculture and agro-industry as managers and leaseholders or supervisors of farms. The duration of the studies would be three years and as students were admitted young men over the age of 16 who had certificate of attendance and completion the $\mathrm{B}$ grade of secondary school. The students were either boarders or non-boarders. Also, the fees and tuition paid by the students annually, the number of students, boarders or not, the staff and board configuration were all determined, while, royal decrees were to determine the curriculum, the duties of the staff, the matter of admission and the examinations of students, and many more. The 14th and last article of the law prescribed that the commencement of the school establishment would take place immediately after the bequest was deposited in the National Bank.

The choice of location was anything but random: the main advantage of the location was its geographical position, that is, next to the fertile plain of Thessaly. The region had been indicated, several times before, as appropriate for the operation of an agricultural school. It was one of the three regions (the other two were Athens and Tirintha) where the establishment of an agricultural school had been provisioned according to the bill of 1884 . The choice of Larissa in 1901 is closely related to the wish of the benefactor Georgios Averof, as it was expressed in his will. Certainly, however, the final decision belonged to the government who, of course, showed respect to the benefactor's wish but at the same time deemed the region as the most appropriate thanks to its geographical position and the vast area of the Thessalian plain. The main vision was the 
establishment of a basic educational center of new agriculturists. The main target was the improvement of knowledge of the farming population of the era, so that they could produce more efficiently, process and store their produce in order to cover their family needs and the creation of agricultural executives in the farming areas, whose actions would be an example to other farmers. The ultimate objective was the advancement of "Averofios" into a center of research and study of the land of Greece aiming at a better yield of the cultivations as well as the many-sided development of agriculture (dairy, winery, cheese making, beekeeping, etc.).

Averofios Agricultural School, from the day of its establishment to World War II, created a generation of agricultural executives known as "Meso-agriculturists", who played a significant role in the advancement of agriculture. After World War II the school began to lose its prestige. During the $60 \mathrm{~s}$ and the $70 \mathrm{~s}$ a number of Agricultural Education Centers (KEGEs) were created all over Greece, where farmers could have short education programs covering, this way, to a great extent theirs needs for education and training. Such a center was also established inside Averofios Agricultural School, with huge hotel equipment for the accommodation of farmers and a great number of farming machinery for their training.

Averofios Agricultural School faced many problems as time went by. It operated again after the restoration works on its buildings and this way revived a ninety-year-long history, while these works brought Averofios back into the educational events of Larissa. So, in June 1992, twenty-three years later, certificates were issued to the first 14 agricultural machinery mechanics. Before that date the last certificates had been issued in 1919 .

\section{The Special Characteristics of Its Administration-Management System}

"Averofios Agricultural School" operates as an educational organization oriented towards agriculture and its whole area, which contains 43 buildings, has been designated "listed", which is protected by the Ministry of Culture. Five different institutions, four central ones and a management board are involved in the management of the school:

(a) The Hellenic Public real Estate Corporation, since it is located on public land.

(b) The Ministry of Finance, through the Directorate of Public Welfare Property.

(c) The Ministry of Culture, due to the designation of the area (the buildings as well as the surrounding site) as protected.

(d) The Ministry of Agricultural Development and Food, since it is a farming oriented school.

Also, the Board of Management of the bequest gets involved in the whole administration and management system and its role is focused on the proper implementation of the benefactor's will stipulations. On the contrary, bodies of local authority do not get involved in its management which means that they do not have any ability to intervene. Next, the study presents the specific characteristics that emerge due to the involvement of many different institutions in the administration and management system of the school, leaving the involvement of the Ministry of Agricultural Development and Food last, since it is believed to be the clearest and simplest one in the whole suggested planning.

4.1 "Averofios Agricultural School" as "Public Property"

The School is sited on "public property". "Property" in general is anything that can be owned, public or non-public. "Public property" is called anything of which the state has the full ownership, either in the form of public possession or that of private possession. Public property includes "non-traded public properties", "the state private properties" and "special property categories".

According to the Civil Code (articles 966, 967, 968, 970, 971) the non-traded (public acquisition) 
properties include: first, "the common to all" (sea, air, water, etc.) which are not dominated but the state exercises sovereignty over them; second, the "shared" or "communal" (e.g. seashore, deds of perpetually flowing waters, navigable river banks, large lakes and their shores, roads-squares-pavements, railway lines, gardens, woods and antiquities); third, those intended to serve budgetary purposes (e.g. churches, monasteries, cemeteries).

The "state private properties" (Private Acquisition) include properties that passed to the state mainly by succession of the Turkish State; by forced expropriation or by purchase contract; third as abandoned; fourth as generated by sediment left by the sea.

The "special property categories" include exchangeable land (that is, land abandoned by the Turks after the exchange of populations, as well as land belonging to the church and other institutions known as "vakoufia") and bequests (that is, property passed on to the state, municipality, community or other legal or individual entity so that they will use it for public benefit and is passed on to them through a will, a donation).

The basic difference between the two first types is that the "non-traded" can not be exported as long as they bear this characterization, while those belonging to the type "state private property" can undergo exportation. Also, the "shared" ones become "state private" when they cease to be commonly shared for public, communal or religious purpose, which means that they can be sold, e.g. a discontinued road, a drained lake, old foreshore zone (after change of its determination).

The Ministry of Finance manages the part of Public Property, which does not belong to other Ministries and covers a wide range, both on property types and on total managed area. On central level this management is controlled by the General Directorate of Public Property and Public Welfare Property and by the Central Hellenic Public Real Estate Company
(KED), while on regional level it is controlled by the local offices of Public Property that operate in the capital of every prefecture and KED units.

Consequently, given the fact that the School is located on "public land", and this land, as well as all the other properties, is under the superintendence, control and management of the newly established Hellenic Corporation of Assets and Participations (overseeing privatization actions) to which has passed the total of the public real estate and private property of the Hellenic State. Practically, therefore, the land is potentially for sale, despite any consequences on the school itself, its future and any scenarios concerning its development.

\subsection{Averofios Agricultural School as a "National Bequest"}

The jurisdiction of the Ministry of Finance services over public property, which on regional level are controlled by KED units, also concerns bequests. In the case of the School this jurisdiction is controlled not on regional but a central level, as it has been characterized as National Bequest. It is reminded here that a bequest is defined as "property passed on to the state, municipality, community or other legal or individual entity so that they will use it for public benefit and is passed on to them through a will, a donation, etc." Consequently, given that the School is a national bequest it is under the control and the management of the Public Real Estate Company, as far as the land on which it is located is concerned and the management of the Ministry of Finance as far as the bequest itself is concerned (that is, the initial sum of money donated for the specific purpose, namely the establishment and operation of the school). It is noted here that Averofios is a bequest that "determines" and "prescribes" only its use which, according to the degree of its implementation, has been completed and fulfilled. Thus, from legal perspective the criterion of location on "public land" is superior to the criterion of "a bequest", a fact that means that its land is 
"claimable" in case such a claim is raised, since the stipulations of the will have been fulfilled and they do not concern the land.

\subsection{The School as "A Work of Art and Preserved Historical Monument"}

In 1993, there was a decision by the Ministry of Culture (FEK 182/B/19-3-1993), according to which the buildings of the School surrounded by a wood bearing the same name, were designated, after a proposal of the school itself, "a work of art and preserved historical monuments", as it is a distinguished, representative sample of a building complex of educational nature and has distinctive morphologic and architectural characteristics. It is worth noticing that many of its buildings are "twins".

The characterization of a building as preserved means restrictions on its ownership, since the owner is required not to proceed in arbitrary actions which change the building or "damage", either the whole of it or its distinctive artistic characteristics, nor its use. This is considered a just restriction on ownership, since it prevents the property from disappearing or from becoming idle, as regards its use. Besides, in article 17, paragraph 1 of the Constitution there is a general proviso concerning "public interest", which allows the legislator to introduce restrictions concerning the orientation of the property or its use, on condition that the core of this right is not abolished. According to the Council of State this restriction must obey the principles of proportionality and equality and the necessity for it to be applied must be justified.

The designation of the School as "work of art and historical preserved monument" entails benefit as well as cost, which, however, to a great extent, is "relevant" given the distinct nature of the "owner". The present study will focus on presenting the cost only, because it is the possibility of intervention in the building stock. For example, the special nature of the buildings requires the existence of specialized care, which as a rule is quite expensive. At the same time, any kind of works and interventions, even the most insignificant, needs the notification in advance and the intervention of the public institutions that have a say and the right to intervene and suspend any works. All of the above make the whole procedure even more complex, given the fact that in the case of the School the involved institutions are many and diverse.

\section{Synthesis-Discussion: Proposal for the Evolution and Revitalizasion of Averofios Agricultural School}

The preceding analysis showed the distinctive characteristics of the School which, in any case, have to be taken into account in case the evolution and revitalization of the School are set as a target. According to the analysis: the School is a national bequest, which was established after Georgios Averof's donation to the Greek state in order for institutions to be created, which would aim at the fulfillment of national, communal and charitable objectives. Every national bequest is determined by a will. In this case, the existing will dictates and restricts only the use of the bequest, that is, the School must always be of educational nature. As a national bequest, it is subject to the control and management of the Ministry of Finance and its relevant directorate.

However, at the same time the School is located on public land, therefore it is subject to the control and management of the Public Real Estate Company, namely of "TAIPED" (Hellenic Republic Asset Development Fund) in contemporary Greece with the economic crisis and austerity memorandums. At the same time, the operation of the School is subject to the supervision of the Ministry of Agricultural Development and Food and its respective directorate. Besides all of the above, we have to take into consideration that all the buildings (45 in total) and the surrounding area have been characterized as "preserved" in 1992, which means that any works needed are subject to the control, management and 
supervision of the Ministry of Culture and the respective Directorate of Protection and Restoration of Modern and Contemporary Monuments. Finally, it is a site-monument located in the Municipality of Larissa, within the city-planning limits of the main urban plot.

According to the institutional criteria of categorization and classification of cultural heritage, the School is a stationary monument, non-point (extensive), of the modern era (that is, built after 1830). However, according to the nine spatial criteria of cultural heritage classification, which aim at the more rational and more effective management of it in the frame of planning, the School is characterized by the following (Table 1).

Of the above, positive is considered the satisfaction of criteria: 3 (monument alive/inhabited, since it is a school in operation), 5 (under protection, since it is characterized as a work of art and a historical preserved monument, the whole of defined area) and 6 (accessible, therefore potentially exploitable).

On the contrary, negative are considered criteria: 7 (a monument with a huge part of it derelict and in need of restoration) and 9 (of a complex ownership and managing status).

Criterion 7 means that the monument's revitalization requires extensive interventions and, consequently, huge funding, which, in a period of financial crisis and memorandums, is very difficult to be found. Thus, seeking funds from the European Union is a one-way solution and prerequisite for any development of the monument. Despite that, criterion 9 can be even more important, since it refers to the ownership status. The management situation concerning the School is a complex one and many different entities are involved. At the same time, its ownership status is not clear, which makes any development and attempt for revitalization of the school quite difficult. Above, the complexity of the ownership and the management status were described so that their significance could be highlighted. In any case, it is considered crucial that this status be made clear and, after that, the procedure regarding the concession of the monument to the local authority — which has already expressed grave interest in its further development.

The inclusion of the monument in the jurisdiction of the Municipality of Larissa is considered to be the best solution given the nature of the monument and its need for immediate renovation, at least. Furthermore, along with any procedures followed, it is emphasized that the entity responsible for the educational operation of the school needs to change. It is reminded that the school is supervised by the Ministry of Agricultural Development and Food, which is regarded as a fact that downgrades the school and keeps it isolated from all the other educational institutions located in the area of Larissa city. In this framework, it is suggested that the above jurisdiction be transferred to the Ministry of Education, that is, the entity that supervises all the educational, academic and research institutions of Greece.

\section{Table 1 Spatial classification characteristics of Averofios Agricultural School.}

\begin{tabular}{lll}
\hline & Criterion & Characterization \\
\hline 1 & Spatial morphology & Extensive/residential (housing) ensemble (?) \\
2 & Spatial integration & Out of the urban web/ in extra-urban area \\
3 & Integration in human activities & Alive/inhabited (part of it) \\
4 & Operation and use & Educational use \\
5 & Protection status/degree & Under protection \\
6 & Utilization degree & Accessible/visitable \\
7 & Condition & In bad condition/ in need of restoration/derelict \\
8 & Value and range & Local \\
9 & Ownership & Public (?) \\
\hline
\end{tabular}


The above mentioned transfer is believed to bear a lot of benefits given the existence of analogous educational institutes in the city of Larissa, and even better, on the same side of the city. The School (1), the Technical Institute of Larissa (TEI) (2), the University of Thessaly (3) and the National Institute of Agricultural Research (4) are all located in the eastern area of the city forming an "imaginary" line, thus, a uniform "educational-operational" unit. The geographical adjacency is given and obvious and so is complementarity. They are all educational institutes of different levels which can, however, form synergies and co-operations (both vertical and horizontal), since they are involved in similar scientific fields or, potentially, they can get involved (e.g. agricultural, biotechnological research). The creation of an educational hotspot and, in the medium-term, a cluster of relevant enterprises is obviously quite ambitious but not impossible, given the fact that there are some of the prerequisites along with the fact that the area itself has ample land available for cultivation and further development.

Criteria 4 (educational use) and 8 (local) are considered neutral, based on the existing condition of the School, but they can develop to negative ones it its financial sustainability, at least, is taken into account along with its "brand name", regarding any potential future added value. The "educational use" and the "local range" of the monument can not by themselves ensure a sustainable future and become a basic ingredient of the spatial identity of the city of Larissa or of the country, in the long run. The main issue is the preservation, exploitation and elevation of the school in such a way that the future generations will be able to enjoy it and reap the benefits of such a project. Consequently, any suggestion concerning the development and revitalization of the School must aim at the future, building on and developing the present, though; that is on the existing condition. In this framework, the present study suggests the development and revitalization of the School so that it becomes an agricultural educational park whose creation should take place along with a number of other actions in order for its sustainability to be reinforced.

Averofios Agricultural School as an agricultural educational park will obviously retain and expand its educational purpose. The whole idea is based on the creation of a number of educational, environmental and aesthetic services of agricultural orientation and of co-operations which will produce collateral benefits for the city of Larissa, first, and for the greater area and the country, secondly. Along with its purely educational operation, though, "Averofios" park:

(1) will retain the existing cultivable land and will obtain more.

(2) will increase general public's access to it.

(3) will help farmers by providing access to cultivable land or/and by offering possibilities for further support through incubators and training actions.

(4) will offer ample space for walking, pic-nicks and other recreation activities.

(5) will operate as a uniform region, place and infrastructure which will provide a valuable habitat and will offer services concerning education and planning of ecosystems, water catchments and environmentally sustainable agricultural practices.

(6) will offer assistance with funding issues via projects concerning ground leases, agricultural production and other specialized events.

However, Averofios Agricultural Park has to be escorted by a number of various actions in order for its sustainability to be ensured. These actions concern mainly the greater urban, spatial and strategic planning. To achieve this objective the School has to network with other cultural heritage attractions, to be connected not only to the neighboring urban center (the city of Larissa) but also to other cities (cities of Thessaly and other cities with agricultural tradition and relative heritage throughout Greece and abroad), to be enriched and supported with more spaces and 
infrastructure (the erection of a museum is possible as there is already a lot of farming machinery and equipment exhibited on its premises) and, obviously, to ensure adequate accessibility to the monument (the School has no specific transport connection with the city, while bicycle lanes and pedestrian paths leading to the school do not exist). Furthermore, the School must become part of a local cultural route (the routes could be homogenous or heterogenous), in order to get connected with the other cultural networks and goods of the area (such as, the other city attractions) and it must include some other uses with relevant or supplementary content (the creation of food services and the establishment of a horse riding center in the wood which is part of its premises could be actions towards this target).

Finally, any proposition concerning the School has to include touristic aspects, as well. Besides, there is already a hostel for its students in operation, which, however, is vacant during the summer months. The touristic development suggested is a mixture of cultural and educational tourism with "agricultural specialization". Moreover, cultural and educational tourism is special, alternative form of tourism which goes beyond the narrow limits of an urban network. The desired result is the contact, familiarization and acquisition of knowledge (both more and less scientific) on traditional produce, culture, customs and manners etc. The main advantages of this type of tourism are that it is not connected with a specific time of the year, contributes to the further dispersion of tourism and attracts people with interest in it, who usually belong to a high educational level and have a high income.

\section{Conclusions}

Cities participate in actions aiming at the conservation and protection of cultural heritage through urban planning procedures. In fact, the conservation and protection of cultural heritage is included or should be included in this planning, since cultural development and its incorporation into cities are faced and regarded, or should be faced and regarded, as a valuable strategy aiming at accelerating the procedures of urban development or revitalization. Cities invest in cultural facilities, operations and events, as well as in the preservation of their heritage. However, to what extent do, let us say, historical monuments and places form an instrumental part of a city, that is, they are fully incorporated into the regular, everyday life of the city? Both the incorporation and the integration of cultural heritage constitute prerequisites for the transition of a city from the agro-industrial economy to the post-industrial, that is, an economy that is based on advanced services, on mixing operations, facilities and uses in a sustainable way and on the high quality of the urban environment.

Averofios is a bequest of the national benefactor Georgios Averof. It was established in 1901 and operated in 1911. It constitutes a turning point of the agricultural education in Greece. It was the first Agricultural University of the country and it is referred in the novelist's M. Karagatsis work Colonel Liapkin. It is a place which used to be a reference point for the older Larissa dwellers. However, urbanization, industrial development and abandonment of agriculture, little by little, brought about the downgrade and degeneration of the school. Almost 100 years later, the School strives to move ahead bearing a glorious past and facing an uncertain future. The lack of personnel, the abandonment and the non-existent allocation of funds for the maintenance of the listed buildings and the other premises of the School, make up a setting of an obviously neglected, almost derelict area. An area located in the "heart" of the Thessalian prairie and whose name is synonymous with the progress and development of agriculture in the Greek history.

What can be done for a monument like Averofios Agricultural School is difficult to answer. Conversation over the issue at hand is easy and even easier is to direct the conversation towards specific 
suggestions, either feasible or less feasible, a sustainable suggestion is hard to be made, though, nowadays when the country is in a financial crisis and in a bailout programme. There is the option of non-action, which will lead to further obsolescence and eventually to total abandonment. There is also the choice of facing the School as a cultural good, that is, a stationary, non-point (extensive) monument of cultural heritage, in accordance with the provisions of the Greek and International legislature and other competent authorities. Following an approach as this, the issue of the School has to be faced and prioritized in the frame of a broader planning (on national, regional and local level) whose value will be interpreted as an index of social prosperity and development and, long term, will become a touristic (and consequently a financial and developmental) resource.

The proposal discussed in the present study, that is, the evolution and regeneration of the School into an educational agricultural park which will also be part of a broader attraction point including entities such as the Technical Institute of Thessaly, the University of Thessaly and the National Institute of Agricultural Research, is believed to move towards the correct direction. The proposal respects the history of the School and its quality as a good and cultural heritage monument, it "builds" on the image of Larissa City, that is, the common belief that it is a dynamic, agricultural city located in the center of Greece, and lays the foundation for a sustainable future for the School. Obviously, it is self-evident that the above mentioned "plan" concerning the School has to be part of the broader city planning, first of all, as well as, of the regional authorities planning so that the necessary by-products can be produced and be dispersed throughout the country, since Greece is a small country and any such attempt must have a national scope, namely, the plan has to be supported by corresponding policies and funding.

\section{References}

[1] Florida, R. L. 2002. The Rise of the Creative Class: And How It's Transforming Work, Leisure, Community and Everyday Life. New York: Basic Books.

[2] Geppert, N. A. 2014. "Planning Systems Facing Heritage Issues in Europe: From Protection to Management, in the Plural Interpretations of the Values of the Past." European Spatial Research and Policy 21 (2): 9-12.

[3] Greffe, X. 2004. "Is Heritage an Asset or a Liability?" Journal of Cultural Heritage 5 (3): 301-9.

[4] Heilbrun, J. 1992. "Art and Culture as Central Place Functions." Urban Studies 29 (2): 205-15.

[5] Kunzmann, K. R. 2004. "Culture, Creativity and Spatial Planning." Town Planning Review 75 (4): 383-404.

[6] Landry, C. 2000. The Creative City: A Toolkit for Urban Innovators. London: Earthscan.

[7] Scott, A. J. 2001. "Industrial Revitalization in the ABC Municipalities of São Paulo: Diagnostic Analysis and Strategic Recommendations for a New Economy and a New Regionalism." Regional Development Studies 7: $1-32$.

[8] Tweed, C., and Sutherland, M. 2007. "Built Cultural Heritage and Sustainable Development." Landscape and Urban Planning 83 (1): 62-9.

[9] Vecco, M. 2010. "A Definition of Cultural Heritage: From the Tangible to the Intangible." Journal of Cultural Heritage 11 (3): 321-4.

[10] Vos, W., and Meekes, H. 1999. "Trends in European Cultural Landscape Development Perspectives for a Sustainable Future." Landscape and Urban Planning 46 (1-3): 3-14. 